\title{
Long Standing Diabetes on Insulin - is it Possible to Stop Insulin, Lose Weight and still have Glycaemic Control? - Case Report
}

\author{
Kalyan Kumar Gangopadhyay ${ }^{1}$ and Awadhesh Kumar Singh ${ }^{2}$ \\ ${ }^{1}$ Department of Endocrinology, Fortis and Peerless Hospital, India \\ ${ }^{2}$ Department of Endocrinology, GD diabetes Institute, India
}

Submission: February 06, 2019; Published: March 27, 2019

*Corresponding author: Kalyan Kumar Gangopadhyay, Department of Endocrinology, Fortis and Peerless Hospital, Kolkata, West Bengal, India

\section{Abstract}

Type 2 diabetes mellitus (T2DM) is a progressive disease and as the disease progresses, insulin therapy becomes necessary in at least $50 \%$ of patients with T2DM. The administration of very high insulin doses has inherent challenges including weight gain, absorption problems with high volume of insulin as well as compromising on patient acceptance, comfort and compliance. Thus, it is important to have treatment options that combine insulin-sparing agents with insulin to minimize both insulin volume and side effects. The glucagon-like peptide-1 receptor agonists/ analogues (GLP-1 RAs) provide an attractive option for the same. Here, I present two cases wherein addition of liraglutide to high dose insulin therapy, relatively late in the disease process, led to complete cessation of insulin therapy as well as weight loss.

Keywords: Diabetes mellitus; Insulin therapy; Ischemic heart disease; Glucose levels; Premixed insulin; Weight gain; Oral medication; Glycaemia control; Metformin; Endothelial dysfunction; Dyslipidaemia; Hypertension; Cardiovascular disease

Abbreviations: T2DM: Type 2 Diabetes Mellitus; GLP-1: Ras: Glucagon-Like Peptide-1 Receptor Agonists/Analogues; CSII: Continuous Subcutaneous Insulin Infusion; MDIs: Multiple Daily Injections; TDID: Total Daily Insulin Dose

\section{Case 1}

A 62-year-old man with type 2 diabetes mellitus (T2DM) of 30-year duration came for consultation to the out-patient department. He had a past history of ischemic heart disease for which he underwent coronary artery bypass grafting (CABG) in January 2012.

The patient had been well initially on oral medication, until 2012, when glucose levels became increasingly difficult to control; and he was eventually initiated on premixed insulin, doses titrated up to 48 units and 16 units, before breakfast and before dinner respectively. He was also receiving voglibose 0.3 mg twice daily, before meals.

He responded initially to insulin therapy, however subsequently his glycaemia control started deteriorating. His HbA1c level started rising and he also gradually gained weight, with his BMI touching $30 \mathrm{~kg} / \mathrm{m} 2$ for which he was quite distressed.

In July 2013, he was initiated on liraglutide, a glucagon-like peptide receptor analogue, and dose titrated from $0.6 \mathrm{mg}$ to 1.2 $\mathrm{mg}$ a month later and eventually, $1.8 \mathrm{mg}$ four months later. Over the 1. years that he was on liraglutide, his HbA1c improved from $6.9 \%$ to $6.4 \%$, insulin requirement came down to nil (from 64 units per day) and the only other anti-diabetic agent he remained on was metformin $500 \mathrm{mg}$ once daily. Moreover, since initiating liraglutide he lost $12.5 \mathrm{kgs}$ of weight (from $82.5 \mathrm{~kg}$ to $70 \mathrm{~kg}$ ) which relieved his distress and made him feel better.

\section{Case 2}

A 45-year old obese woman, with poorly controlled T2DM of 10-year duration presented, in May 2012, with high blood sugars (FPG - 245mg/dL and PPG - 274mg/dL). She was started on premixed insulin 22 units before breakfast and 28units before dinner. 6-months later her glycemic control improved (FPG - 151mg/dL and PPG - 153mg/dL), after which her regimen was changed to insulin glargine 25 units at bedtime, as she requested for a once-a-day insulin. Subsequently, she was given a trial of various other anti-diabetic agents, including vildagliptin and metformin, both of which had to be stopped due to gastroenterological intolerance, and finally her glycaemic control settled with insulin glargine 25 units at bedtime and $2 \mathrm{mg}$ of glimepiride twice daily. 


\section{Current Research in Diabetes \& Obesity Journal}

She was doing well with this regime throughout 2013. However, towards the end of 2013 her glycaemic control started deteriorating once again and she presented in February 2014 with an $\mathrm{HbA1c}$ of $9.8 \%$ and weight of $90 \mathrm{~kg}$. She was initiated on liraglutide, gradually up-titrated from $0.6 \mathrm{mg}$ to $1.2 \mathrm{mg}$ and maintained on the same. Over the last one year, there was a remarkable improvement in her overall well-being. Her HbA1c improved from $9.8 \%$ to $6.9 \%$, insulin requirement came down to zero (from 50 units per day) while she continued with glimepiride $2 \mathrm{mg}$ twice daily and voglibose $0.3 \mathrm{mg}$ once a day, which was introduced subsequently. She lost $12 \mathrm{kgs}$ of weight (from $90 \mathrm{~kg}$ to $78 \mathrm{~kg}$ ) and is continuing the present treatment.

\section{Introduction}

Type 2 diabetes mellitus (T2DM) is a progressive disease with complications affecting several organ systems. Diabetes is reaching epidemic proportions globally; the prevalence estimated to reach 592 million by 2035 [1]. T2DM is the most prevalent type of diabetes, accounting for $90-95 \%$ of cases [2]. T2 DM has increased 93-fold in women and 42-fold in men who are severely obese rather than those of ideal weight $[3,4]$. In the short term, even modest weight loss in people with T2DM, who are overweight or obese, is associated with improvements in glycaemic control and associated conditions such as hypertension and dyslipidaemia [5].

As the disease progresses, insulin therapy becomes necessary in at least 50\% of patients with T2DM [6]. Although an effective treatment for hyperglycemia, insulin is associated with undesirable side effects including hypo glycaemia and weight gain. The global obesity epidemic is driving the need to deliver ever-increasing doses of insulin to the ever-increasing obese, insulin-resistant diabetic population. The administration of very high insulin doses has inherent challenges viz. keeping the volume of insulin sufficiently small for optimal absorption, without compromising on patient acceptance, comfort and compliance. Thus, it is important for patients with T2DM and with high insulin requirements to have treatment options that combine insulin-sparing agents with insulin to minimize both the insulin volume and weight gain [7]

The glucagon-like peptide-1 receptor agonists/analogues (GLP-1 RAs) are injectable incretin hormones associated with improvements in glycaemic control and with low risk of hypoglycaemia, when used alone or together with metformin. They augment insulin secretion and reduce glucagon secretion, thus improving glycaemic control in patients with type 2 diabetes. These agents also exert beneficial effects on body weight by centrally increasing satiety and slowing gastric motility $[8,9]$. Patients with poor glycaemic control, increased body mass index (BMI), and using higher insulin doses are generally difficult to treat optimally due to insulin resistance and weight gain associated with the increasing insulin dosages $[10,11]$. Delivering high insulin doses may require multiple injections and/or very high volume injections, which can lead to suboptimal absorption, patient discomfort and non-compliance with the prescribed insulin regimen. This has led to an increase in the use of concentrated U-500 insulin over the past decade [12], especially in the Western countries, and the advent of U-200 and U-300 insulin.

\section{What the Evidence Says}

GLP-1 RAs have been shown to lower the insulin dose and mitigate insulin-associated weight gain compared to treatment with basal insulin alone in metformin-treated patients with type 2 diabetes [13-15]. The various study programs on the various GLP1RAs have demonstrated similar results.

However, data on addition of GLP1 RAs to high-dose intensive insulin therapy are sparse. A study by Lane et al. [7], conducted on subjects with T2DM of 17.7 years duration, requiring more than 100 units of insulin daily; administered either by continuous subcutaneous insulin infusion (CSII) or by multiple daily injections (MDIs); with or without metformin, has shown that after 6 months of therapy with liraglutide, $67 \%$ of subjects experienced $>20 \%$ reduction in the total daily insulin dose (TDID) and 33\% experienced $<20 \%$ reduction.

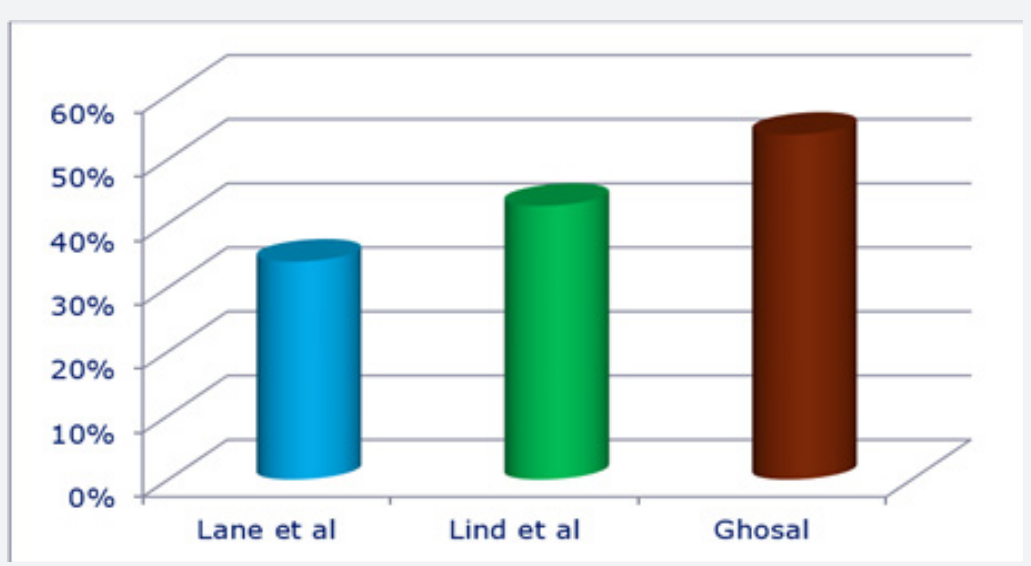

Figure 1: Percentage reduction in the TDID after addition of GLP1RA to existing insulin treatment $[7,16,17]$ 
Lind et al presented similar results from 4 Swedish centers, wherein an average of 38.6, units' reduction in TDID from baseline was reported. In this cohort, a significant proportion of patients were on MDI and premixed insulin, 52.5\% and $11.5 \%$ respectively. The mean duration of diabetes in this cohort of patients was 14.6 years [16].

Table 1: Summary of studies where GLP1 RAs were added to existing insulin treatment $[7,16,17]$.

\begin{tabular}{|c|c|c|c|c|}
\hline Author & No. of Patients & Insulin Dose at Baseline (U) & Insulin Dose at End of Study (U) & 132 \\
\hline Lane [7] & 21 & 199 & 52.2 & $\mathrm{x}$ \\
\hline Lind [16] & 65 & 91.1 & 29.7 & $30 \%$ stopped insulin \\
\hline Ghosal [17] & 22 & 64.4 & \\
\hline
\end{tabular}

\section{Conclusion}

There seems to be a sub-set of patients in whom initiating GLP1RA therapy later in the disease process and treatment continuum will have beneficial effects. Patients with T2DM with high insulin requirements are severely insulin resistant and at high risk for cardiovascular disease. Moreover, a high dose of insulin therapy contributes to significant weight gain and obesity which is associated with a host of complications, viz. endothelial dysfunction, dyslipidaemias, hypertension and an increased risk of cardiovascular disease, amongst others. In patients with advanced insulin regimens, GLP1RAs seem to be a viable treatment option with low risk of hypoglycaemia, weight loss and high treatment satisfaction, resulting from decreased requirements of insulin. The most attractive feature in this subset of patients is the insulin-sparing effect; a notable number of patients could be weaned off insulin completely. Due to limited treatment options in patients with poor glycaemic control and high dose insulin therapy, the combination of insulin therapy and GLP-1 RAs seems promising and definitely worth exploring.

\section{Conflict of interest}

KKG has received speaker honoraria from Eli Lilly, Novo Nordisk, Sanofi Aventis and MSD.

\section{References}

1. (2013) International Diabetes Federation. IDF Diabetes Atlas. $\left(6^{\text {th }}\right.$ edn.), Brussels, Belgium, USA.

2. (2011) World Health Organization. Fact Sheet No.312.

3. Colditz GA, Willett WC, Rotnitzky A, Manson JE (1995) Weight gain as a risk factor for clinical diabetes mellitus in women. Ann Intern Med 122(7): 481-486.

4. Chan JM, Rimm EB, Colditz GA, Stampfer MJ, Willett WC (1994) Obesity, fat distribution, and weight gain as risk factors for clinical diabetes in men. Diabetes Care 17(9): 961-969.

5. Pi-Sunyer X, Blackburn G, Brancati FL, Bray GA, Bright R, et al. (2007) Reduction in weight and cardiovascular disease risk factors in individ-
Ghosal evaluated the addition of liraglutide in Indian T2DM patients uncontrolled on insulin + OAD, with a mean duration of diabetes of 12.8 years. He reported a 53.8\% reduction in insulin dose in the study population and about a third of the patients were able to stop insulin [17] (Table 1 \& Figure 1).

uals with type 2 diabetes: one-year results of the look AHEAD trial. Diabetes Care 30(6): 1374-1383.

6. Harris M (1996) Medical care for patients with diabetes - epidemiologic aspects. Ann Intern Med 124: 117-122.

7. Lane W, Weinrib S, Rappaport J, Hale C (2014) The effect of addition of liraglutide to high-dose intensive insulin therapy: a randomized prospective trial. Diabetes Obes Metab16(9): 827-832.

8. Lovshin JA, Drucker DJ (2009) Incretin-based therapies for type 2 diabetes mellitus. Nat Rev Endocrinol 5(5): 262-269.

9. Shyangdan DS, Royle PL, Clar C, Sharma P, Waugh NR (2010) Glucagon-like peptide analogues for type 2 diabetes mellitus: systematic review and meta-analysis. BMC Endocr Disord 10: 20.

10. (1998) Intensive blood-glucose control with sulphonylureas or insulin compared with conventional treatment and risk of complications in patients with type 2 diabetes (UKPDS 33). Lancet 352(9131): 837-853.

11. D Russell-Jones, R Khan (2007) Insulin-associated weight gain in diabetes - causes, effects and coping strategies. Diabetes Obes Metab 9(6): 799-812.

12. Lane WS, Cochran EK, Jackson JA, Scism-Bacon JL, Corey IB, et al (2009) High-dose insulin therapy: is it time for U-500 insulin? Endocr Pract 15(1): 71-79.

13. Buse JB, Bergenstal RM, Glass LC, Heilmann CR, Lewis MS, et al. (2011) Use of twice-daily exenatide in basal insulin-treated patients with type 2 diabetes: a randomized controlled trial. Ann Intern Med 154(2): 103112.

14. Vora J, Bain SC, Damci T, Dzida G, Hollander P, et al. (2013) Incretin-based therapy in combination with basal insulin: a promising tactic for the treatment of type 2 diabetes. Diabetes Metab 39(1): 6-15.

15. Tzefos M, Olin J (2012) Glucagon-like peptide-1 analog and insulin combination therapy in the management of adults with type 2 diabetes mellitus. Ann Pharmacother 44(7-8): 1294-1299.

16. Lind M, Jendle J, Torffvit O, Lager I (2012) Glucagon-like peptide 1 (GLP-1) analogue combined with insulin reduces $\mathrm{HbA1c}$ and weight with low risk of hypoglycemia and high treatment satisfaction. Prim Care Diabetes 6(1): 41-46.

17. Ghosal S (2011) Using Liraglutide in Combination with Insulin Therapy for Type 2 Diabetic Patients: An Early Clinical Experience Data. Presentation no: 1144-P, presented at the American Diabetic Associations $71^{\text {st }}$ Scientific Sessions, San Diego, California, USA, pp. 1144. 


\section{Current Research in Diabetes \& Obesity Journal}

This work is licensed under Creative

Commons Attribution 4.0 Licens

DOI: 10.19080/CRDOJ.2019.10.555786
Your next submission with Juniper Publishers

will reach you the below assets

- Quality Editorial service

- Swift Peer Review

- Reprints availability

- E-prints Service

- Manuscript Podcast for convenient understanding

- Global attainment for your research

- Manuscript accessibility in different formats

( Pdf, E-pub, Full Text, Audio)

- Unceasing customer service

Track the below URL for one-step submission https://juniperpublishers.com/online-submission.php 